\title{
A New Proposal to Teaching: The Beehive Interactive Learning Model in a Statistics Course
}

\author{
Gulsah BASOL \\ Gaziosmanpasa University, Faculty of Education, Department of Educational Sciences, Turkey
}

\begin{abstract}
The purpose of the study is to present the Beehive Interactive Learning Model (BILM) and to provide an example of its application in an undergraduate statistics course. The model is developed by the researcher, who is a professor in Educational Measurement and Evaluation area in Turkey with over 15 years of teaching experience. The model is based on four main components; content, instruction, assessment, and motivational beliefs. The core principal of the model is to stimulate students' desire for learning. Both the instructor and the students are in the center of the model, placed in the beehives, referring to the hard work and constant interaction among students. The graphical representation of the model is presented in the paper. The model has been improved over a period of 10 years by adding new components and omitting some. The model requires the instructor to encourage active learning through class projects and performance assignments. It heavily relies on technology and the Internet; course portal provides online documents, an opportunity to download and submit assignments online, and to take online self-regulated quizzes with instant feedback. There are lab sessions requiring students to demonstrate their analyzing skills in SPSS. The model aims to pack the knowledge in a way that awakens everybody's desire to learn, satisfies the learner through successful hands-on applications and finally develops a sense of success, hopefully yielding positive attitudes toward the content and learning. The model is in the process of development and any suggestions are welcomed from the researchers around the world.
\end{abstract}

Keywords: Beehive Interactive Learning Model (BILM), learning, teaching.

\section{Introduction}

There are many ways a teacher can teach as there are many ways a student can learn. A quick search leads us to four learning theories; behavioralist, cognitivism, constructivism, and collectivism. In terms of the learning perspective, behavioralism and cognitivism apply teacher-centered instruction, while the constructivism and collectivism are more student-centered. In behavoiralism, learning is considered as a response to an external stimulus. Coginitivism takes it a little further by considering learning as a process of acquiring and keeping the knowledge. Therefore learning is seen both as an internal and external process. In cognitivism, the instructor is responsible for helping students store and recall the knowledge as needed. Constructivism considers learning as a process of building the knowledge. In the learning process, we are aware that the knowledge is constructed over the previous information which the student already knows. Instructor's responsibility is to keep the learners active and encourage social interaction. In the student-centered classes, students are welcome to take a part in the design of each class according to their needs. Finally, in connectivism, learning is considered as a process of connecting different sources of knowledge in a network by the use of technology, therefore Internet. Among these, connectivism is the one which heavily relies on technology.

Eccles and Wigfield (2002) divided the learning theories into four categories. These are theories focused on expectancies for success (self-efficacy theory and control theory), theories focused on task value (intrinsic motivation theory and selfdetermination, flow, interest and goals), theories that integrate expectancies and values (attribution theory, the expectancyvalue models and self-worth theory), theories integrating motivation and cognition (social cognitive theories of selfregulation and motivation), and at last theories of motivation and volition). In the same study, Eccles and Wigfield (2002) argued how to integrate theories of self-regulation and expectancy-value models of motivation. 
Bandura (1977) developed the Social Learning Theory (SLT), stating behaviors, thoughts, feelings, attitudes and the social environment molds an individual's personality. In SLT, Bandura stated the importance of mediating mental factors for an individual to observe the behavior and imitate it. In the Behaviorist Model, the link between the stimulus and the response is considered as a black box, the source can be anything (e.g. beliefs/attitudes, motives, needs, perceptions); however, in cognitive model it is called as a mediational process occurring between the input and the output behavior. Bandura proposed four mediational processes: Attention, retention, reproduction, and motivation. We do not expect someone to repeat a behavior he/she did not notice (attention); in order to repeat the behavior he/she must recall it (retention); if it is learned, he/she can do it again as needed/wanted (reproduction); and finally anything is possible if he/she has the desire or the will to do it (motivation). The importance of will power on learning certainly was known from the beginning of mankind. Bandura (1997) was the first to suggest self-efficacy beliefs for facilitating effective instructional environment. He clearly defined and related it to the learning behavior. The sense of self-efficacy, also called confidence as commonly used, is explained as a source playing a major role in how one approaches a problem, goal, task, or a challenge. According to Bandura (1997), self-efficacy is ones belief in ones ability to succeed in specific situations or accomplish a task. Bandura stated that the current or past personal experiences of the learner are the most important source of self-efficacy. Therefore we can conclude that someone who had negative attitudes toward math would end up having a negative attitude toward statistics.

Over the years, SLT has become very influential on learning and development as considered by some researchers; e.g. Nabavi (2012) as the most influential. It is sometimes referred to as a "bridge" between behaviorist and cognitive learning theories because it encompasses attention, memory, and motivation (Munoz, n.d.). It is so much so that Ormrod (2008) called the SLT, Social Cognitive Theory. The way cognitive, behavioral, personal, and environmental factors interact with each other and influence the behavior is emphasized in Bandura's Social Cognitive Theory (Crothers, Hughes, \& Morine, 2008) as Triadic Reciprocal Determinism. Therefore reorganizing the environment, changing the beliefs about the course, or reshaping students' self-perceptions about themselves can influence their learning skills. Self-regulation is another source positively affecting student's learning. Self-regulated e-tests are regarded positively to increase student's selfregulatory skills in studies that frequent e-tests were offered to the participant students (Basol \& Balgalmıs, 2016; Maurer \& Longfield, 2015; Maurer, 2006).

The purpose of the current paper is to introduce a new learning model called "The Beehive Interactive Learning Model" with an illustration of its application on a topic in a statistics course. Beehive Interactive Learning Model, developed by the author in her classes is based on a constructivist and connectivist perspective. The model heavily relies on the computer and Internet. The conceptualization of the model is provided in Figure 1.

\section{Fig. 1. Beehive Interactive Learning Model}

The name beehive refers to the hard work expected both from the instructor and students. There are four main components of the model; three on the sides and one in the center. The ones on the sides are content, instruction, and assessment. Motivational beliefs are in the core of the model throughout the course. The students and the instructor were placed in honey combs next to each other, suggesting maintaining instruction among students also between them and the instructor.

\section{Beehive Interactive Learning Model}

The Beehive Interactive Learning Model was developed over 13 years of teaching experience by the researcher.

Four Main Components of the Model

The model has four main components; content, instruction, assessment, and motivational beliefs.

\subsection{Content}

The model requires a blended course enriched by the use of flipped classroom activities, online quizzes with instant feedback opportunity. The design of the content in BILM will be explained in the Statistics II course taught by the author in the spring semester of 2017 in Gaziosmanpasa University. Statistics II was offered to the undergraduate program of Psychological Counseling area. In the statistics II course, which the model was applied there were seven main application skills that were aimed. 
These were preparation of the data set, $z$ tests, $t$ tests, ANOVA, correlation, regression, and factor analysis. The semester lasted 14 weeks. Statistics I was offered in the fall semester to sophomores and all of the registered students that had taken statistics I in the previous semester. They were familiar with SPSS and were already able to obtain, review, and make comments on descriptive statistics and graphics. Therefore, we could say that the model is more suitable for courses requiring application level skills, graphical demonstrations, and memory of visual illustrations. BILM answered the needs in statistics II both for the students and the instructor. In the following heading, the instruction of the model is explained in detail.

\subsection{Instruction}

The main instructional tool is the course portal. The course was designed as a blended Leaning Management System on MOODLE. The system has been active in World Wide Web since 2011. Students register to the system through their student ID and then have access to the course portal through Gaziosmanpasa University's Learning Management System (Ims.gop.edu.tr).

In Figure 2, a screenshot of the course portal is provided.

\section{Fig. 2. A Screenshot of Statistics II Course Portal}

The main content of the course was defined by the Higher Education Council of Turkey and regular weekly courses were supported with blended learning environment through MOODLE. The course portal provided a link to download the materials for Statistics II. The syllabus was provided as well, covering the weekly topics and the course requirements. As an example, the instruction of independent $t$ test was explained in detail.

\subsubsection{An Example of the Instruction of BILM}

First, the topic was covered in the regular weekly class session. A brief explanation about Student's $t$ test was provided and students encouraged sharing their ideas on how they can use the independent $t$ test when they become a school counselor. By this application, the instructor expected students to be more interested and involved in the remaining of the course. Later the instructor explained the test a bit more in detail, provided the assumptions for independent $t$ test, and showed the formula followed by an example to practice how to calculate the test by hand. As the assumptions were provided, students were asked to recall how each assumption was tested as they learned it in statistics I. Each assumption was recalled by reviewing how they were checked and how it was decided whether they were met or not. Thinking aloud and discussion among students were allowed in this process to make them enjoy discussing statistics and feeling the togetherness. In the third step, the instructor demonstrated how to run $t$ test in SPSS by the use of data in the example. Screenshots of the process were also included in a PPT slide covering the highlights of the class. These notes were provided in the course portal beforehand and most of the students brought it to class. As the instructor calculated the problem on the blackboard, students confirmed the result from their notes. It was not a requirement but as the students studying in this manner got better in the course, this application was followed by others, especially the girls. SPSS screenshots were also in the handouts. As they see how easily they can calculate or get it done in SPSS, the instructor expected students to feel a relief about their assignments.

Students had to prepare a portfolio, covering assignments on the preparation of the data set, $z$ tests, $t$ tests, ANOVA, correlation, regression, and factor analysis. In the course portal a detailed check list for each assignment was provided to help students to review and self-control their work and also to maintain a certain standard in the assignments. They were free to work alone or in groups up to three students if they wish. Students were required to make up their own problem associated with psychological counseling area, make up the data, calculate by hand and in SPSS and make their tables and write up their findings according to APA style. The instructor prepared a study sheet for each analysis, containing an example of each test. In Table 1, the check list for independent $t$ test is provided.

Table 1. The Check List for Independent $t$ Test 
For SPSS analysis, students were able to follow the videos in the instructor's YouTube channel. The videos were accumulated over the years according to the requests made by the students in the classroom sessions. As the instructor realized that students use their smart phones to take videos in the class, she made the recordings and shared them on YouTube and let them known through the class' Whatsapp group. This also helped students who miss a class occasionally. Through the semester as requested, the video of a certain application could be found online as the instructor demonstrated it in class.

\subsubsection{Instructor's Role in BILM}

In terms of the instructor's role in the model, the instructor must be a guide and a facilitator. The instructor introduces the content; makes it sound easy by either referring or linking to the previously learned content. It is also essential to show that it is simple by hands on experiences. Step-by-step examples calm students about the assignments and encourage them to do it in a timely manner. Check lists were introduced right after the work was assigned, therefore students would know what was expected from them. According to students' point of view, flipped learning was useful and overall students favored it above anything else which had been performed to ease their learning throughout the semester. They could stop the videos anytime they wanted and review the material as they wished while they progressed with their homework. It was great for topics requiring sequential instruction.

Flipped classroom application was found to be a useful strategy for performance assignments in the statistics course. The lecture demonstration videos were also provided. The diagrams, graphs, and charts from the news were encouraged to be shared in the classroom so that students could experience real life examples. Anything that could help them learn was applied e.g. storytelling, to drama, simulations, and applying statistical analysis to sample data and etc. As an example, to explain the difference in corresponding table values for .05 and .01 confidence levels in a one-sided test, the instructor picked a student and made him/her stand on one tail and explained the change in the table values. For two tailed-tests, the table values and the area between the mean and the sides were explained by the use of one student in each tail. This was repeated and the values corresponding to the critical levels were written and once completed it was read aloud to make it seen and heard, as well.

\subsection{Assessment}

Over 15 years as an instructor, by constructing new items for every class, the author ended up having an item bank of over 11 hundred test items in statistics. She realized the urge students had to see the sample test items before the exam; the more they were anxious about a course, the more questions they asked about the exam e.g. what they should expect in the exam, how difficult it would be, how many questions they are going to be asked, and so on. Therefore, the idea of offering self-regulated quizzes and trial tests for midterm and the final exam was appealing. In the author's courses (Statistics, Measurement and Evaluation), students have a chance to do so since 2011.

In terms of assessment, formative self-regulated e-quizzes with instant feedback play an essential role in the model. Selfregulation is an abstract concept, often studied as an important factor influencing student achievement (Basol \& Balgalmis, 2016). Self-regulation has three phases; forethought, self-reflection, and performance (Zimmerman, 2005). In BILM, all of these three phases are reflected. Since there are many sources students can use, they can review the material and decide how to go about it. Later, students carry on each step by themselves, forming the problem and the data, calculation, analysis and the write up part. They not only submit the portfolio, also perform in the lab session requiring them to demonstrate SPSS analyses on a data set provided by the instructor. Therefore, one can easily see whether a student can perform all the analyses covered in the course on a sample data set, make the right conclusions in a limited time. During the lab sessions students were allowed to ask questions, request help and work with a peer as they needed. In case they received help, they needed to perform the analysis with another variable other than the one they used with the peer mentor's guidance. The peer mentors were the students who completed their lab work early and wanted to help their classmates. There was no punishment for failure; students knew that in case they could not succeed, their lab sessions would be rescheduled. Their performance was awarded with stars and peer mentors received an extra star for their help. The focus was not on the grade, lab sessions were more like a chance to sit down and practice every analysis they learned in the presence of the instructor. The lab sessions were regarded highly by students. There was not a single student who left the lab without completing the work assigned.

\subsection{Motivational Beliefs}


As it can be seen in Figure 1, motivational beliefs are in the core of the model and should be considered in each step of the instructional design. As widely accepted, it is not possible to improve learning by solely concentrating on learning strategies for that motivation is the source yielding students to study.

The effect of many cognitive and meta-cognitive strategies on learning is widely acknowledged and their relation to achievement is studied in various subjects at differ rent educational levels.

According to Pintrich, Smith, Garcia, and McKeachie (1991), motivational beliefs are cognitive behaviors and meta cognitive strategies; including intrinsic motivation, extrinsic motivation, and task value (referred to as value components), control of learning beliefs and self-efficacy for learning and performance (called expectancy component), test anxiety (mentioned as an affective component). Cognitive and meta-cognitive strategies are reported as rehearsal, elaboration, organization, critical thinking, self-regulation, time and study environment, effort regulation, peer learning, and help seeking behavior (Pintrich, Smith, Garcia, \& McKeachie, 1991). Intrinsic motivation is the behavior driven from internal rewards which may not be recognized visually in most occasions. Extrinsic motivation refers to outside rewards and punishments affecting one's desire to learn. The problem with this is that it is hard to know what to use for students coming from different backgrounds and to what extend it could have an effect. Task value refers to the student's evaluation of the task in terms of its usefulness; again it could be a challenge to change students' perceptions of the task since most of the time it can be manipulated by the students. Control of learning beliefs is about whether the student believes the effort he/she puts into class would be rewarded. Most of the time the student who scored too low in the mid-term quits studying being convinced he/she would fail no matter what. In the current application of BILM, the grade was a function of various components (performance in the assignments, portfolio check, midterm exam, final exam and the performance in the lab sessions) so that there was not too much emphasis placed on the midterm or any others. There were students who scored less than 20 out of 100 points; however, they were assured by the instructor that they still had a chance as long as they reviewed what they did wrong and found out how they should have studied and did it right from any point.

Through the techno-enriched instruction and hands-on experiences, it was expected to increase students' intrinsic motivation by building passion for work, positive attitudes toward learning and teaching, eagerness to try, expressing confidence, resilience, help-seeking and giving behavior, increasing self-efficiency, self-regulation, and appreciation of knowledge. From beginning to end, students were encouraged to do their assignments through assuring them it was easy, useful and worth learning. The instructor answered some of their questions or guided them elsewhere so they could build self-reliance and experience joy by finding something they had been looking for. It was claimed that while taking a bath in a public bath house, Archimedes realized that the more his body sank into the water, the more water was displaced. He walked out of the bath screaming "Eureka! Eureka!", which means "I found it! I found it!" (Cited by Biella, 2006). By guiding students to the right direction, the instructor helped them find the answer by themselves. Dispositions are defined as frequent and voluntary habits of thinking and doing (Da Ros-Voseles \& Haughey, 2007). It is also referred to as characteristics and wrongly used interchangeably with traits and skills (Colker, 2008). As highlighted in Da Vas Vosales and Fowler-Haughey (2007) and pointed out in Colker (2008), traits are unconscious behaviors, while skills are more likely to be the result of conscious teaching efforts. BILM suggests that the instruction should aim at more than just attaining the specific teaching goals of the course. With proper education, it is possible to help students gain positive attitudes towards both learning and teaching e.g passion for work, sense of responsibility, time-management skills, sharing rather than give and take based-relationships, being organized, following the commands and etc.

The purpose of Beehive Interactive Learning Model is to improve learning, help students have a better grasp of their knowledge by encouraging them to communicate with each other and implement this knowledge to their self-proposed problems which are similar to real life scenarios. At the beginning of the class the weight is on the instructor. Then, it gradually shifts to students through the examples, questions and performance tasks. In this model, student participation was aimed to be increased through planned activities for retention purposes. The instructor praised every effort for learning; students were encouraged to complete their tasks without any pressure; such as working to a deadline, being graded, and test anxiety.

\section{Conclusion}


The motivational beliefs, purposed to be improved by the use of BILM in its current application in Statistics II are explained shortly. First, the Beehive Interactive Learning Model is expected to improve student learning by designing the course in a way offering various techno-enriched instructional sources (e.g. frequent online quizzes, flipped classroom activities, online course documents), along by decreasing the stress level by hands-on application opportunities, well-structured and guided performance assignments, with an emphasis on increasing the motivation and self-efficacy skills by assignments.

Pintrich, Smith, Garcia, \& McKeachie (1991) mentioned task value as a meta-cognitive strategy improving learning. In BILM, the instructor put a lot of effort to relate the content to real life situations through the assignments and the lab sessions hoping that it would increase the task value of the content. Self-regulation is another meta-cognitive variable that is expected to be improved by the application of self-regulated e-quizzes and the assignments with no deadline in BILM. In the current application of BILM, using multiple instruments for grading helped the instructor build positive perception regarding the control of learning beliefs, suggested also as a meta-cognitive learning strategy. Students were interested in the concept and were highly motivated at all levels from the beginning to the end. Providing a sample problem with the solution and being able to review how to do videos for each analysis made students believe that assignments were manageable, therefore these efforts were expected to increase the self-efficacy level of students.

Detailed control lists to review the performance in assignments were useful for the instructor to maintain a certain standard in the assignments and for the students to get a sense of how well they were doing. The assignments were not graded through a rubric since they were used to diagnose the missing points and make timely corrections. The instructor reviewed the student portfolio in the presence of the student by focusing on the rights, praising the student for the effort, and at last pointing out the mistakes by explaining how to do it correctly. In the review process, volunteer peer mentors also checked the portfolios in the presence of the instructor, arguing whether it was acceptable to do an analysis in a certain way. The more they took part in this activity, the more the peer mentors got better in statistics. After directing the student to the right source (to a certain video recording or study sheet), a new meeting was scheduled as needed. This application purposes teaching through evaluation process and it is not present in any other teaching models. One-to-one portfolio evaluation can be referred to as a personalized evaluation. It was beneficial to understand whether students understood what they did in the assignments, how deep their knowledge was. One-to-one portfolio evaluation can also be considered as a way of improving interaction among students and between the student and the instructor. BILM creates a classroom environment full of worker bees in the guidance of a queen bee, also being the reason the model is named Beehive Interactive Learning Model.

In the BILM, frequent online testing opportunity is purposed to decrease test anxiety as well, an affective component (Pintrich, Smith, Garcia, \& McKeachie, 1991) usually regarded negatively although it is known to have a positive effect on achievement to some extent. Basol-Gocmen (2004) suggested frequent testing as an instrument to keep students on the ball and therefore reduce their test anxiety (Basol-Gocmen, 2004). Being able to solve similar test items to the ones in the midterm and final exam was relaxing and since the emphasis was on the assignments and the portfolio, teaching to the test effect was not expected to occur. If the emphasis were on the mid-term and the final tests, students would see the frequent online exam only as an opportunity to pass the course. Basol \& Balgalmis' research (2016) which frequent e-tests were applied as an instructional tool suggested that self-regulated students take this opportunity more often. It would be interesting to search whether taking e-tests was helpful in overcoming the fear of failing a course. The researcher suggests BILM to the instructors who have an item bank, and to ones with sufficient knowledge of computer enriched instruction; such as MOODLE, Blackboard, WEBCT, YouTube, and GDrive. So far the model has been applied in courses provided by the author to the undergraduate level teacher candidates (Statictics I, Statistics II, Measurement and Evaluation). It would be impressive to see the application of BILM on a course other than the ones stated and at different educational levels. BILM offers a new way to teaching and any instructor who has a genuine interest in improving his/or teaching skills is welcomed to use BILM.

\section{References}

[1] Bandura, A. (1997). Self-efficacy: The exercise of control. New York: W.H. Freeman.

[2] Bandura, A. (1977). Self-efficacy: Toward a unifying theory of behavioral change. Psychological Review, 84(2), 191.

[3] Basol, G., \& Balgalmıs, E. (2016). A multivariate investigation of gender differences in the number of practice tests and quizzes controlling for perceived self-regulation. Computers in Human Behavior, 58, 388-397.

[4] Basol-Gocmen, G. (2004). Meta Analysis. Journal of Eurasian Educational Research, 15, 16-22. 
[5] Biello, D. (2006). The famed mathematician made many important scientific contributions. Was this exclamation really one of them? Scientific American, Retrieved from https://www.scientificamerican.com/article/fact-orfiction-archimede/

[6] Colker, L. J. (2008). Twelve characteritics of effective early childhood teachers, Journal of the National Association for the Education of Young Children, 63(2), 68-73.

[7] Crothers, L. M., Hughes, T. L., \& Morine, K. A. (2008). Theory and cases in school-based consultation: A resource for school psychologists, school counselors, special educators, and other mental health professionals . New York: Routledge Taylor \& Francis Group. Retrieved from http://books.google.com/books?id=vKsXLZkKiylC

[8] Da Ros-Voseles, D. \& Haughey, S. F. (2007). Why children's disposition should matter to all teacher. The role of dispositions in the education of future teachers. Young Children, 62(5), 90-98.

[9] Eccles, J. S., \& Wigfield, A. (2002). Motivational beliefs, values, and goals. Annual Review of Psychology, 53, 109-132.

[10] Maurer, T. W., \& Longfield, J. (2015). Using reading guides and on-line quizzes to improve reading compliance and quiz scores. International Journal for the Scholarship of Teaching and Learning, 9(1), 1-22.

[11] Maurer, T. W. (2006). Daily online extra credit quizzes and exam performance. Journal of Teaching in Marriage \& Family, 6, 227-238.

[12] Munoz, L. (n.d.). Social learning theory. Retrieved from https://lynnmunoz.wordpress.com/learningtheories/social-learning-theory-aka-social-cognitive-theory/

[13] Nabavi, R. T. (2012). Bandura's social learning theory \& social cognitive learning theory. Theory of Developmental Psychology. 1-24.

[14] Ormrod, J. (2008). Human Learning (5th ed.). New Jersey, NY: Pearson Education, Inc.

[15] Pintrich, P. R., Smith, D.A.F., Garcia, T., \& McKeachie, W. J. (1991). A manulak for the use of Motivated Strategies for Learning Questionnaire. ERIC Document Reproduction Service No. ED 338 122. Retrieved July, 14, 2017, from EBSCOHost ERIC database.

[16] Zimmerman, B. J. (2005). Attaining self-regulation: A social cognitive perspective. In M. Boekaerts, P. Pintrich, \& M. Zeidner (Eds.), Handbook of self-regulation (13-39). San Diego, CA: Academic Press.

\section{TABLES AND FIGURES}

Fig. 1. Beehive Interactive Learning Model

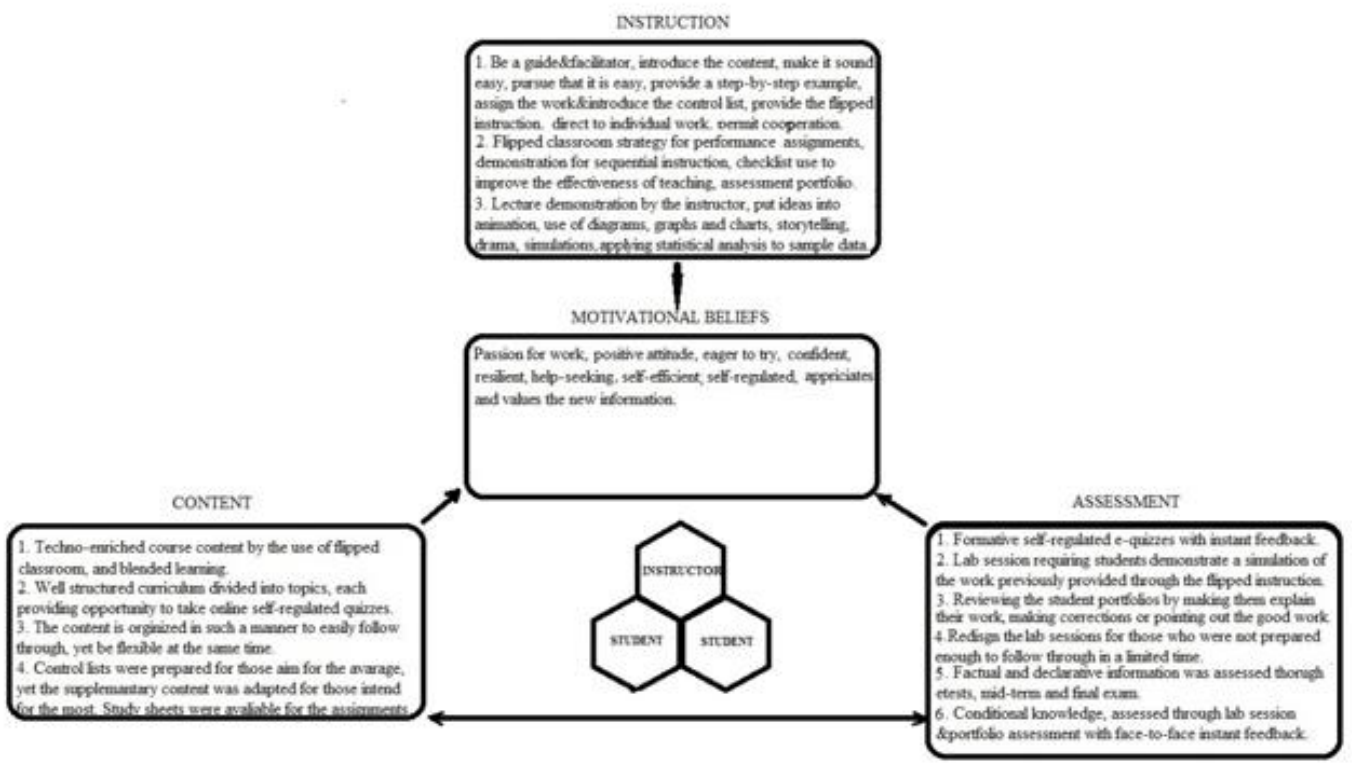


Fig. 2. A Screeshot of Statistics II Course Portal

Fig. 2. A Screeshot of Statistics II Course Portal

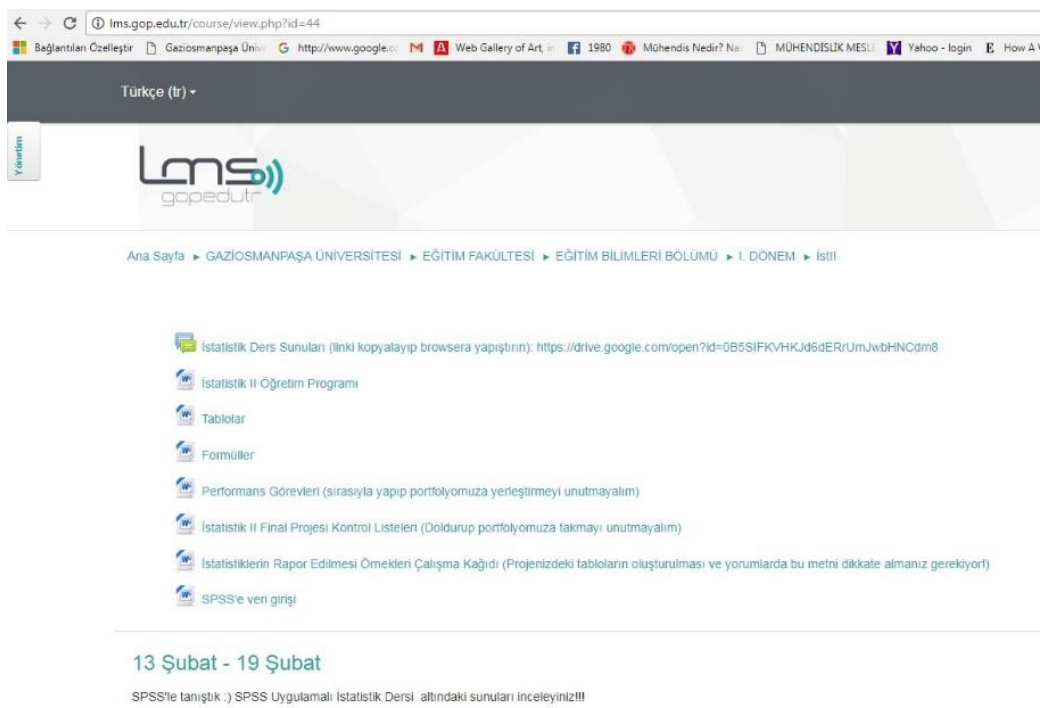

Table 1. The Check List for Independent $t$ Test

\begin{tabular}{|l|c|c|}
\hline$t$ test Check List (2) & Yes & $\begin{array}{l}\mathrm{N} \\
0\end{array}$ \\
\hline $\begin{array}{l}\text { 1. Do you have an orijinal t test problem statement? (Dependent variable, a continous variable in interval } \\
\text { or ratio scale, independent variable, a categorical variable in nominal scale with two levels) }\end{array}$ & & \\
\hline 2. Are your hypotheses suitable to your problem statement? (one way or two ways) & & \\
\hline $\begin{array}{l}\text { 3. Do you have a self-constructed data set for your problem? (Complete the assumption check, search } \\
\text { for an outlier, normality, and homogeneity of variances) }\end{array}$ & & \\
\hline 4. Do you have the formula in your assignment provided in class for $t$ test? & & \\
\hline 5. Did you complete the hand calculations with the correct formula? & & \\
\hline $\begin{array}{l}\text { 6. Did you find the correct table value for your problem? Did your hypothesis hold? Was your conclusion } \\
\text { suitable to your findings? }\end{array}$ & & \\
\hline 7. Did you calculate the effect size and make your conclusion? & & \\
\hline 8. Did you provide screen shots of your analysis? & & \\
\hline 9. Did your SPSS results match your hand calculations? & & \\
\hline 10. Can you explain $t$ test, when it is used, its assumptions, and its non-parametric alternative? & \\
\hline
\end{tabular}

